Check for updates

Cite this: RSC Adv., 2018, 8, 30201

Received 11th July 2018

Accepted 17th August 2018

DOI: 10.1039/c8ra05903a

rsc.li/rsc-advances

\section{Organic photovoltaics of diketopyrrolopyrrole copolymers with unsymmetric and regiorandom configuration of the side units $\uparrow$}

\begin{abstract}
Kenta Aoshima, (iD a Marina Ide ${ }^{a}$ and Akinori Saeki iD *ab
Diketopyrrolopyrrole (DPP) is a representative electron acceptor incorporated into narrow-bandgap polymers for organic photovoltaic cells (OPV). Commonly, identical aromatic units are attached to the sides of the DPP unit, forming symmetric DPP polymers. Herein we report the synthesis and characterization of DPP copolymers consisting of unsymmetric configurations of the side aromatics. The unsymmetric DPP copolymer with thienothiophene and benzene side moieties exhibits good solubility owing to the twisted dihedral angle at benzene and regiorandom configuration. A significant shallowing of the highest occupied molecular orbital level is observed in accordance with the electron-donating nature of the side units (benzene, thiophene, and thienothiophene). The overall power conversion efficiencies of the unsymmetric DPPs (2.3-2.4\%) are greater than that of the centrosymmetric analogue $(0.45 \%)$, which is discussed in view of bulk heterojunction morphology, polymer crystallinity, and spacecharge-limited current mobilities. This comparative study highlights the effect of unsymmetric design on the molecular stacking and OPV performance of DPP copolymers.
\end{abstract}

\section{Introduction}

The need to meet a rising global demand for renewable energy sources has led to the exploration of materials for nextgeneration solar cells. As such, organic photovoltaic cells (OPV) based on a bulk heterojunction (BHJ) framework have been developed, ${ }^{\mathbf{1 - 4}}$ in particular over the last two decades, wherein a bicontinuous network of binary ${ }^{5-7}$ or multiple $\mathrm{b}^{8-10}$ components consisting of p-type and n-type conjugated materials is central to the photoelectric conversion process. The materials used include polymers and molecules that are mostly composed of covalently-bonded electron-donating and electronaccepting units to manipulate their electrochemical properties such as bandgap $\left(E_{\mathrm{g}}\right)$ and intermolecular interactions such as crystallinity $^{11,12}$ and backbone orientation. ${ }^{13,14}$

Diketopyrrolopyrrole (DPP) ${ }^{15-23}$ and isoindigo (IDG) $)^{24-34}$ are relatively strong electron acceptors and have been polymerized into narrow-bandgap polymers for OPV. Based on modification of IDG, Ashraf et al.,$^{35}$ Pruissen et al. ${ }^{36}$ and Koizumi et al. ${ }^{37}$ have reported the synthesis of thienoisoindigo (TIDG) and its copolymers as organic field-effect transistors (OFETs), which is followed by applications of TIDG-based near-infrared (IR)-

${ }^{a}$ Department of Applied Chemistry, Graduate School of Engineering, Osaka University, 2-1 Yamadaoka, Suita, Osaka 565-0871, Japan.E-mail: saeki@chem.eng.osaka-u.ac.jp ${ }^{b}$ Precursory Research for Embryonic Science and Technology (PRESTO), Japan Science and Technology Agency (JST), 4-1-8 Honcho, Kawaguchi, Saitama 332-0012, Japan † Electronic supplementary information (ESI) available: Synthesis, Tables S1-S3, and Fig. S1-S9. See DOI: 10.1039/c8ra05903a absorbing copolymers to OPV ${ }^{38-42}$ and OFET. ${ }^{43-47}$ IDG and TIDG have structural similarities to DPPs with symmetric side units of benzene $(\mathrm{Ph})$ or thiophene (Th), respectively. However, TIDG exhibits a stronger electron-accepting tendency than Thsandwiched DPP because of the direct attachment of Th to the electron-withdrawing ketopyrrole unit, which leads to a greatly narrowed $E_{\mathrm{g}}$ along with a low open-circuit voltage $\left(V_{\text {oc }}\right){ }^{38}$ Moreover, the most critical issue in the IR-absorbing polymers is that the low short-circuit current density $\left(J_{\mathrm{sc}}\right)$ resulting from the energy bandgap law ${ }^{48}$ causes shortening of the exciton lifetime ${ }^{38}$ through increased coupling with the lowenergy vibrational mode. To balance the exciton lifetime and optical bandgap, Chen et al. ${ }^{49}$ and Ide et al. ${ }^{\mathbf{5 0 , 5 1}}$ have synthesized a benzothienoisoindigo (BTIDG) unit that replaces one of the Th units of TIDG with Ph (Fig. 1). BTIDG includes an intramolecular attractive $\mathrm{S}-\mathrm{O}$ interaction, and steric hindrance between the proton of $\mathrm{Ph}$ and oxygen of the keto unit, which constitutes a half-distorted $\pi$-plane. This unsymmetric molecular design elicited not only a moderate $E_{\mathrm{g}}$ but also improved

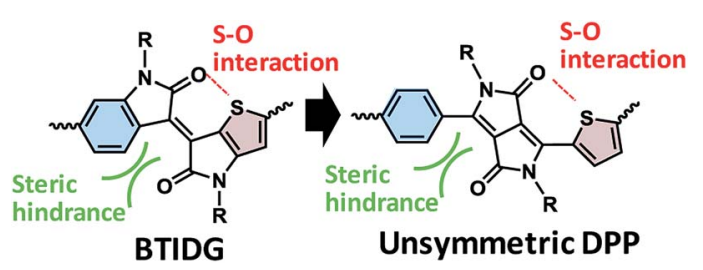

Fig. 1 Molecular design of unsymmetric electron-accepting units. (Left) BTDIG, (right) unsymmetric DPP. 
film morphology (face-on orientation of polymer backbone and miscible BHJ network), resulting in increased power conversion efficiency (PCE). ${ }^{50}$ Thus, the unsymmetric structure and regiorandom configuration of BTIDG copolymers may contribute to the improved film characteristics associated with their solubilities, in analogy to the unsymmetric DPP polymers having Th and thienothiophene (TT) side units (PCE 6\%). ${ }^{21}$

Herein we report a comparative study on DPP-based copolymers with unsymmetric configurations of $\mathrm{Ph}$ and (Th or TT) units. Despite the structural similarity between BTIDG and PhDPP-Th (left and right in Fig. 1, respectively), they behave differently. The morphology, polymer orientation, and spacecharge-limited current (SCLC) mobilities of DPP-based copolymer-[6,6]-phenyl- $\mathrm{C}_{61}$-butyric acid methyl ester (PCBM) blend films are evaluated and discussed, as are their PCEs in an OPV application.

\section{Results and discussion}

Three DPP copolymers were prepared, including a symmetric Ph-DPP-Ph copolymer (P1) as control, an unsymmetric Ph-DPPTh copolymer (P2), and an unsymmetric Ph-DPP-TT copolymer (P3), as shown in Fig. 2. Ph-DPP-Ph rather than more planar and common Th-DPP-Th unit 15,17-23,52,53 $^{\text {was }}$ chosen as control in order to examine the change in the backbone planarization from twist (Ph-DPP-Ph) to half-distortion (Ph-DPP-Th (or TT)) (vide infra). DPP units were synthesized according to previously described procedures (see Experimental) and polymerized with an electron-donor unit of 2-dimensional benzobisthiopheneappending alkylthiophene side units (BDT-Th) via Stille coupling reaction. The resultant unsymmetric DPP polymers are regiorandom, similarly to the pyridylthiadiazole-based molecules and polymers reported by Bazan et al. ${ }^{54,55}$ The weight-averaged molecular weights $\left(M_{\mathrm{w}} \mathrm{s}\right)$ and polydispersity indices (PDIs) of the polymers, as characterized by size exclusion chromatography, were $98.4 \mathrm{~kg} \mathrm{~mol}^{-1}$ (2.7) for P1, $22.2 \mathrm{~kg}$ $\mathrm{mol}^{-1}$ (2.4) for P2, and $31.6 \mathrm{~kg} \mathrm{~mol}^{-1}$ (2.5) for P3. These polymers showed glass transition at $\sim 147{ }^{\circ} \mathrm{C}$ and the identical profiles during two cycles of differential scanning calorimetry (up to $300{ }^{\circ} \mathrm{C}$ ), exhibiting no decomposition below this temperature (Fig. S1†). Solubility of P3 was as large as $\sim 100 \mathrm{mg}$ $\mathrm{mL}^{-1}$ even in toluene at room temperature, which is

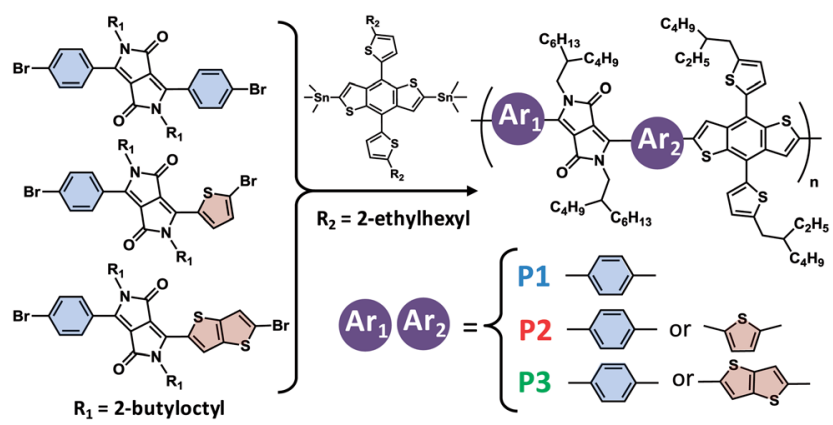

Fig. 2 Chemical structures of the unsymmetric, regiorandom DPPbased copolymers. Polymerization was carried out by Stille coupling method using $\mathrm{Pd}\left(\mathrm{PPh}_{3}\right)_{4}$ catalyst. presumably derived from the twisted backbone at the benzeneDPP connection (vide infra) and unsymmetric, regiorandom configuration. When comparing solubilities of P1 and P3 in toluene-hexane mixture $(1: 1 \mathrm{vol} \%)$, they are well-soluble $(\sim 18$ and $\sim 13 \mathrm{mg} \mathrm{mL}^{-1}$, respectively).

Fig. 3a shows the photoabsorption spectra of P1-P3 in diluted chlorobenzene solutions and as films. All the polymers exhibited mostly unchanged maxima attributed to an intramolecular charge transfer band in both solution and film phases (545 nm for P1, $629 \mathrm{~nm}$ for P2, and $622 \mathrm{~nm}$ for P3). Meanwhile, P2 and P3 exhibited accompanying shoulder peaks in the longer-wavelength region, suggestive of their more extensive conjugation systems and higher crystallinities as compared to P1. Fig. 3b displays the electrochemical properties of the polymers, including the highest occupied molecular orbital (HOMO) levels as evaluated using photoelectron yield spectroscopy (PYS) and the $E_{\mathrm{g}}$ s estimated from the photoabsorption spectra of the films (Fig. S2 $\dagger$ ). The HOMO levels drastically shifted upward, from $-5.62 \mathrm{eV}$ for P1, $-5.37 \mathrm{eV}$ for P2, and $-5.13 \mathrm{eV}$ for P3. The $E_{\mathrm{g}} \mathrm{S}$ of P2 and P3 were very similar (1.67 and $1.66 \mathrm{eV}$, respectively), and are up to $0.4 \mathrm{eV}$ narrower than that of P1 $(2.04 \mathrm{eV})$. The narrowing of the $E_{\mathrm{g}} \mathrm{s}$ and shallowing of HOMO levels are rationalized by the order of the electron-donating strengths of Ph, Th, and TT. Density functional theory (DFT) calculations of donoracceptor-donor units shown in Fig. 3c revealed a contrasting change in the dihedral angle between the BDT-Th donor unit and DPP, where Ph-side angles were almost double (20-25 $)$ those of the Th (or TT)-side angles $\left(11^{\circ}\right)$. The structural planarization of P2 and P3 is likely to partly affect their narrowed $E_{\mathrm{g}} \mathrm{s}$ and the appearance of shoulder peaks (improved crystallinity in a film).

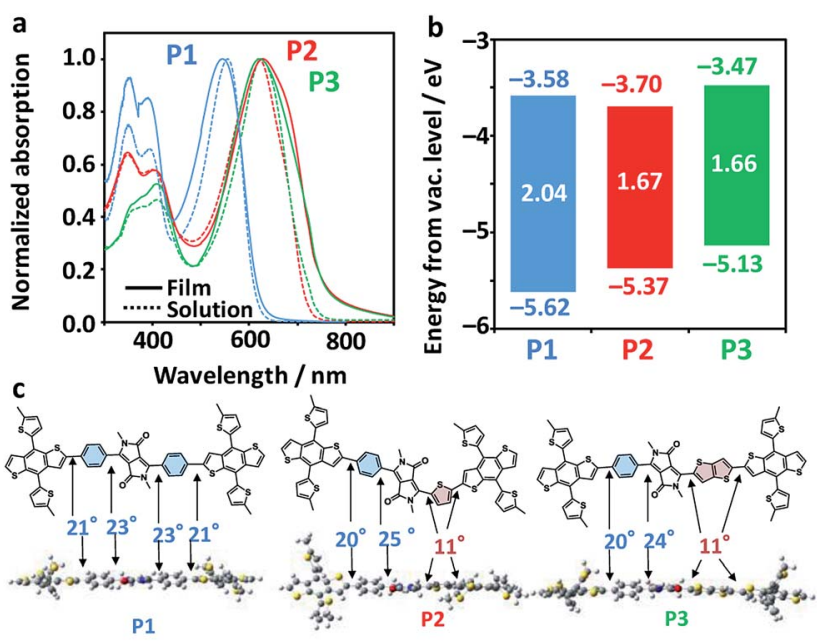

Fig. 3 (a) Photoabsorption spectra of P1-P3 in chlorobenzene solutions (dotted lines) and as films (solid lines). (b) Energy diagram of the copolymers. HOMO (the bottom of each bar) and $E_{\mathrm{g}}$ (the centre of each bar) were evaluated by PYS and the photoabsorption onset in the film, respectively. LUMO (the top of each bar) was calculated by adding $E_{\mathrm{g}}$ and $\mathrm{HOMO}$. (c) Horizontal view, along with dihedral angles at respective bonds. The donor-acceptor-donor compounds were geometry-optimized using DFT with B3LYP/6-31G*. Alkyl chains were replaced by methyl groups to simplify the calculation. 

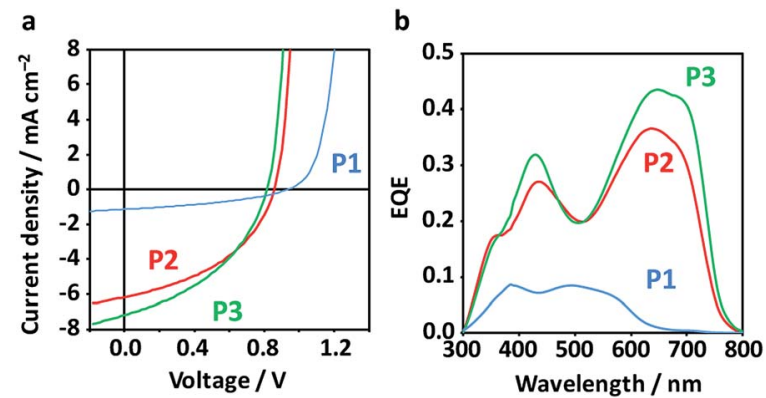

Fig. 4 (a) Current density-voltage curves of the best-performing OPV devices under pseudo-sunlight $\left(100 \mathrm{~mW} \mathrm{~cm}^{-2}\right)$. (b) EQE spectra of the corresponding devices.

Inverted-type OPV devices (ITO/ZnO/active layer/ $\mathrm{MoO}_{x} / \mathrm{Ag}$ ) were fabricated from chlorobenzene solutions with 3 vol\% 1,8 diiodooctane (DIO) as the solvent additive. We have surveyed the processing conditions including thermal annealing (TA, $120{ }^{\circ} \mathrm{C}$ for $\left.10 \mathrm{~min}\right)$ and copolymer : PCBM blend ratios $(1: 1$, $1: 2$, and $1: 3$ ) (Fig. S3 and Table S1 $\dagger$ ). The highest PCE obtained for P1 was $0.45 \%$ (average $0.38 \pm 0.04 \%$ ), while P2 and P3 achieved higher PCEs of $2.30 \%$ (average $1.83 \pm 0.25 \%$ ) and $2.40 \%$ (average $1.97 \pm 0.32 \%$ ), respectively (Fig. $4 \mathrm{a}$ and Table 1 ). The low PCE of control P1 is linked to the coarse BHJ morphology and low crystallinity (low electron mobility, vide infra), while the symmetric copolymer composed of BDT-Th and Th-DPP-Th with the identical alkyl chains have reportedly showed high PCE (1\% (ref. 52) and 6.5\% (ref. 53)). Despite the low PCE of P1, it exhibited the highest $V_{\text {oc }}(0.99 \mathrm{~V})$ among the polymers (P2: $0.875 \mathrm{~V}$ and P3: $0.813 \mathrm{~V}$ ), which is in accordance with the HOMO levels of the respective polymers. The improvement in PCE for $\mathrm{P} 2$ and $\mathrm{P} 3$ is mainly caused by the $J_{\mathrm{sc}}$ $\left(1.25,6.50\right.$, and $7.19 \mathrm{~mA} \mathrm{~cm}^{-2}$ for P1, P2, and P3, respectively), as evident from the large difference in the external quantum efficiency (EQE) spectra (Fig. 4b). The EQE spectra display the same shape as the corresponding photoabsorption spectra of the polymers, and the integrated $J_{\mathrm{sc}}$ over the EQE spectra are consistent with those under pseudo-sunlight exposure $(100 \mathrm{~mW}$ $\mathrm{cm}^{-2}$ ). Note that the small $J_{\mathrm{sc}}$ of P1 is not limited by the narrow $E_{\text {g }}$, but rather is governed by BHJ morphology (vide infra) that simultaneously affects the exciton migration, charge separation, and charge transport. The SCLC hole mobilities $\left(\mu_{\mathrm{h}}\right)$ of pristine polymers monotonically increased from $2.5 \times 10^{-6} \mathrm{~cm}^{2}$ $\mathrm{V}^{-1} \mathrm{~s}^{-1}$ for P1 to $1.0 \times 10^{-5} \mathrm{~cm}^{2} \mathrm{~V}^{-1} \mathrm{~s}^{-1}$ for P2, and further to $8.5 \times 10^{-5} \mathrm{~cm}^{2} \mathrm{~V}^{-1} \mathrm{~s}^{-1}$ for P3 (Table S1 and Fig. S4 $\dagger$ ). In contrast, $\mu_{\mathrm{h}} \mathrm{S}$ of the optimized blend films were low and mostly comparable $\left(2.8 \times 10^{-6} \mathrm{~cm}^{2} \mathrm{~V}^{-1} \mathrm{~s}^{-1}\right.$ for P1 : PCBM, $2.1 \times 10^{-6}$ $\mathrm{cm}^{2} \mathrm{~V}^{-1} \mathrm{~s}^{-1}$ for P2 : PCBM, and $2.2 \times 10^{-6} \mathrm{~cm}^{2} \mathrm{~V}^{-1} \mathrm{~s}^{-1}$ for P3 : PCBM), while the SCLC electron mobilities $\left(\mu_{\mathrm{e}}\right)$ of the blend films increased between P1 $\left(1.4 \times 10^{-5} \mathrm{~cm}^{2} \mathrm{~V}^{-1} \mathrm{~s}^{-1}\right)$ and P2 $(1.9$ $\left.\times 10^{-4} \mathrm{~cm}^{2} \mathrm{~V}^{-1} \mathrm{~s}^{-1}\right)$, and further to P3 $\left(7.9 \times 10^{-4} \mathrm{~cm}^{2} \mathrm{~V}^{-1} \mathrm{~s}^{-1}\right)$ (Table 1 and Fig. S4 $\dagger$ ). The $\mu_{\mathrm{e}}$ values of P2: PCBM and P3 : PCBM, which were an order of magnitude larger than that of P1 : PCBM, agrees with the higher crystallinity of the former polymers (vide infra). Therefore, $\mu_{\mathrm{e}}$, which is closely related to the purity and percolation network of PCBM domains facilitated by the crystallization process of the polymer in the blends, is likely a dominant factor influencing overall PCE.

Surface morphologies of the blend films were observed by atomic force microscopy (AFM), which revealed large circular grains ( $\sim 170 \mathrm{~nm}$ diameter) in P1 : PCBM (Fig. 5a). This contrasted the miscible, small grains observed in both P2 : PCBM and P3 : PCBM ( $\sim 50 \mathrm{~nm}$ diameter). The root mean square (rms) roughness of these height images were mostly comparable: $3.9 \mathrm{~nm}$ for P1 : PCBM, $2.0 \mathrm{~nm}$ for P2 : PCBM, and $3.1 \mathrm{~nm}$ for P3 : PCBM. The 2-dimensional grazing-incidence X-ray diffraction (2D-GIXD) images exhibited weak, less-oriented patterns for all of the blend films (Fig. 5b). The diffraction profile of P3 : PCBM in the out-of-plane (OOP) direction comprises the two peaks attributed to the interlamellar distance $\left(d_{\mathrm{IL}}\right)$ of $1.87 \mathrm{~nm}$ and $\pi-\pi$ stacking distance $\left(d_{\pi \pi}\right)$ of $0.364 \mathrm{~nm}$. The $d_{\mathrm{IL}} \mathrm{S}$ of P1 : PCBM and P2 : PCBM were 1.35 and $1.77 \mathrm{~nm}$, respectively, while their $\pi-\pi$ stacking peaks in the outer region of the hallow due to the alkyl chains (scattering vector $q \sim 14 \mathrm{~nm}^{-1}$ ) were not observed. Regardless of having identical side alkyl chains, the $d_{\mathrm{IL}} \mathrm{S}$ of $\mathrm{P} 2$ and $\mathrm{P} 3$ were larger than that of P1. This is probably due to perturbation of the interdigitation of the side alkyl chains by the winding, regiorandom configuration of the backbone, as seen in the DFT calculations (Fig. 3c). The $d_{\mathrm{IL}}$ of P1 : PCBM was approximately half the end-to-end distance of the expanded 2-ethylhexyl chains of BDT-Th $(\sim 2.7 \mathrm{~nm})$, indicating that the side chains were well-interdigitated. However, the peak was relatively broad, and the crystallite size calculated using Scherrer's relation ${ }^{56}$ was small $(8.4 \mathrm{~nm})$. In contrast, the crystallite sizes of interlamellar and $\pi-\pi$ stacking of P3 : PCBM were 13.5 and $3.1 \mathrm{~nm}$, respectively. The former is obviously larger than those of P1 : PCBM (8.4 nm) and P2 : PCBM (11.5 $\mathrm{nm})$. The same $d_{\mathrm{IL}} \mathrm{S}$ were obtained in the pristine P1-P3 polymers without PCBM (Fig. S5†). Notably, blending with PCBM increased the interlamellar crystallite sizes of P1-P3 from 4.0 to $8.4 \mathrm{~nm}, 4.3$ to $11.5 \mathrm{~nm}$, and 4.1 to $13.5 \mathrm{~nm}$, respectively (Table $\mathrm{S} 2 \dagger$ ). In particular, P3 demonstrated the largest increase, which

Table 1 Summary of polymer : PCBM OPV performances ${ }^{a}$ and SCLC mobilities

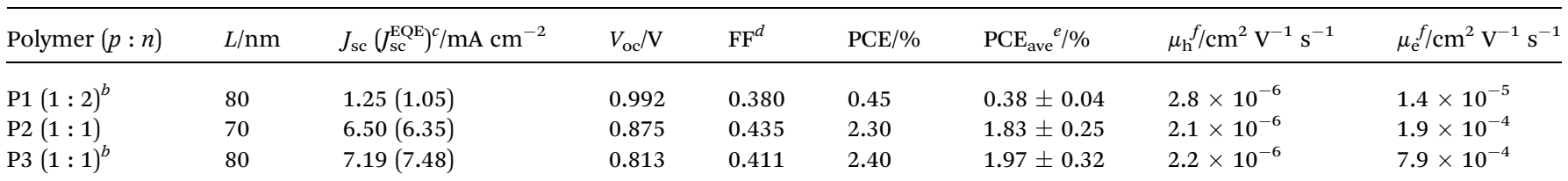

${ }^{a}$ Inverted cell (ITO/ZnO/active layer/ $\left.\mathrm{MoO}_{x} / \mathrm{Ag}\right)$ under simulated sunlight $\left(100 \mathrm{~mW} \mathrm{~cm}{ }^{-2}\right) .{ }^{b}$ Thermal annealing at $120{ }^{\circ} \mathrm{C}$ for $10 \mathrm{~min} .{ }^{c} J_{\mathrm{sc}}^{\mathrm{EQE}}$ is the integrated $J_{\text {sc }}$ over the EQE spectrum. ${ }^{d}$ Fill factor. ${ }^{e}$ Average over at least six devices. The error is a standard deviation. ${ }^{f}$ SCLC mobility of a hole-only device $\left(\mu_{\mathrm{h}}\right)$ and an electron-only device $\left(\mu_{\mathrm{e}}\right)$. 

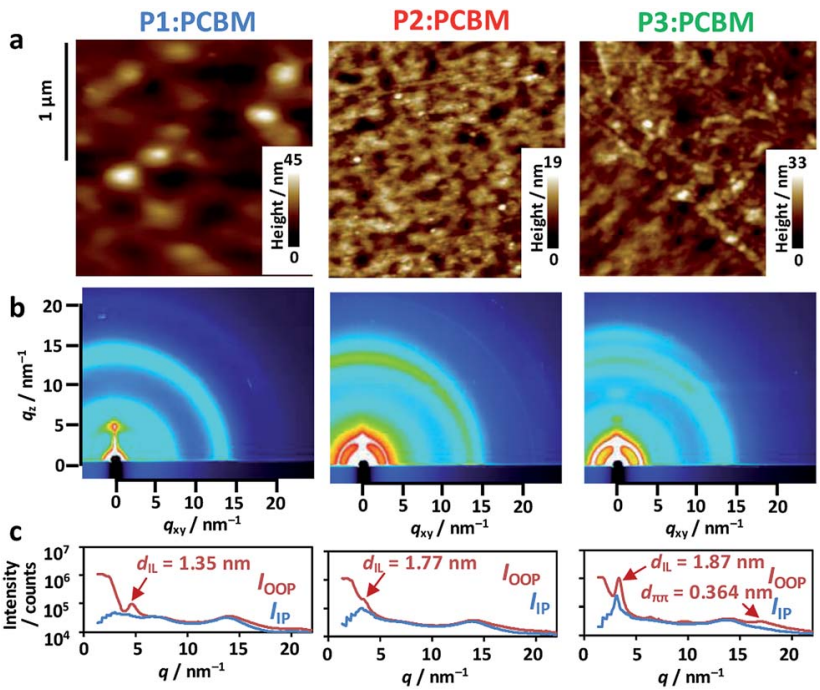

Fig. 5 (a) AFM height images of the P1-P3 copolymer: PCBM blend films. (b) 2D-GIXD images of the blend films. (c) Out-of-plane (OOP, red line) and in-plane (IP, blue line) diffraction profiles. The interlamellar $\left(d_{\mathrm{L}}\right)$ and $\pi-\pi$ stacking distances $\left(d_{\pi \pi}\right)$ are appended.
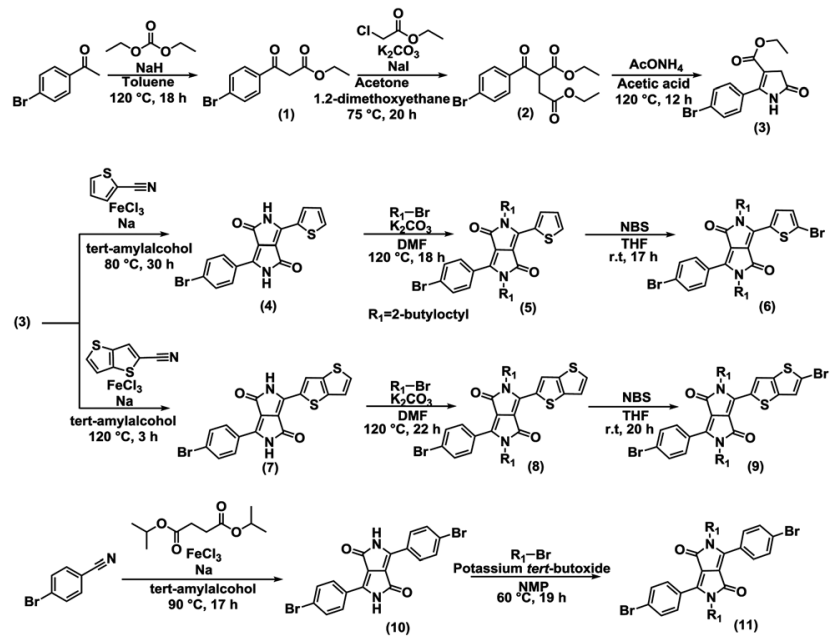

Fig. 6 Synthesis of symmetric and unsymmetric DPP monomers. The enlarged figure and details of the synthesis are provided in ESI. $\dagger$

accompanies the appearance of a $\pi-\pi$ stacking peak in the $2 \mathrm{D}$ GIXD profile. Despite the increased crystallinity in the blend films, hole mobilities were decreased and became comparable among the polymers. This may be due to the decreased connectivity of polymer crystallites, suffered from the presence of PCBM domains in $\mathrm{BHJ}$ films.

\section{Conclusions}

We synthesized and characterized DPP-BDT-Th copolymers having unsymmetric and regiorandom configurations of the side aromatic rings. The unsymmetric DPP copolymers (P2 and P3) showed greater PCEs (2.3-2.4\%) than the symmetric analogue P1 $(0.45 \%)$, which is mainly attributed to the improved $\mathrm{BHJ}$ morphology associated with increased solubility of the unsymmetric polymers. The crystallinities of $\mathrm{P} 2$ and $\mathrm{P} 3$ in their respective PCBM blends were increased as compared to the corresponding pristine films, leading to enlarged crystallite sizes and relatively good $\mu_{\mathrm{e}} \mathrm{s}$. Nonetheless, the insufficient PCEs of P2 and P3 result from the low polymer crystallinities and low $\mu_{\mathrm{h}} \mathrm{S}\left(10^{-6} \mathrm{~cm}^{2} \mathrm{~V}^{-1} \mathrm{~s}^{-1}\right)$ in the PCBM blends as compared to the reported symmetric Th-DPP-Th copolymers (PCE $=6-7 \%){ }^{19,21,53}$ The comparative study shows how an unsymmetric molecular design increases the solubility and affects the film morphology and OPV performance of DPP copolymers, broadening the library of conjugated polymers for applications in organic electronics.

\section{Experimental}

\section{General measurement}

Steady-state photoabsorption spectroscopy was performed using a Jasco V-570 UV-vis spectrophotometer. Molecular weights (weight-averaged: $M_{\mathrm{w}}$ ) and polydispersity index (PDI) of polymers were determined using the size exclusion chromatography (SEC) (gel permeation chromatography: GPC) method with polystyrene standards. SEC-GPC analysis was performed with chloroform as an eluent at a flow rate of $1 \mathrm{~cm}^{3} \mathrm{~min}^{-1}$ at $40{ }^{\circ} \mathrm{C}$, on a SHIMADZU LC-20AT, CBM-20A, CTO-20A chromatography instrument connected to a SHIMADZU SPD-M20A UVvis detector. Photoelectron yield spectroscopy (PYS) of the polymer films on indium-tin-oxide (ITO) glass was performed on a Bunko Keiki BIP-KV2016K instrument. 2D-GIXD experiments were conducted at the SPring- 8 on the beam line BL46XU using $12.39 \mathrm{keV}(\lambda=1 \AA)$ X-ray. The GIXD patterns were recorded with a 2-D image detector (Pilatus 300K). Atomic force microscopy (AFM) was carried out on a Bruker Innova AFM microscope. Differential scanning calorimetry (DSC) was performed using a Netzsch model DSC204F1 Phoenix under $\mathrm{N}_{2}$ at $10{ }^{\circ} \mathrm{C} \min ^{-1}$ (sample weight $=2.1-2.9 \mathrm{mg}$ ). Film thicknesses were measured using a Bruker Dektak XT surface profiler. Solubility of the polymers were measured by dissolving weighted copolymers in chlorobenzene at $80{ }^{\circ} \mathrm{C}$, cooling down to room temperature, filtrating $(0.20 \mu \mathrm{m})$ the solution, weighting the remained copolymer in a filter, and measuring the volume of the solution.

\section{Synthesis of polymers}

Symmetric and unsymmetric DPP monomers were synthesized according to the references (Fig. 6). ${ }^{21,57-61}$ The details of the synthesis are provided in ESI. $\uparrow$ The polymers (P1, P2, and P3) were synthesized via Stille coupling using $\left(\mathrm{PPh}_{3}\right)_{4} \mathrm{Pd}$ catalyst from the relevant Br-DPP-Br monomer and ( $\left.\mathrm{Me}_{3} \mathrm{Sn}\right)-(\mathrm{BDT}-2 \mathrm{Th})$ $\left(\mathrm{SnMe}_{3}\right)$ monomer (Fig. 2). The yields were 36\% for P1, 18\% for $\mathrm{P} 2$, and $75 \%$ for $\mathrm{P} 3$. The ${ }^{1} \mathrm{H}$ NMR spectra of monomers (Fig. S6S8) and polymers (Fig. S9) are provided in ESI. $\dagger$

\section{Organic photovoltaic cell (OPV)}

A ZnO layer was fabricated onto a cleaned ITO layer by spincoating with a $\mathrm{ZnO}$ precursor solution $\left(0.1 \mathrm{~g} \mathrm{~mL}^{-1}\right.$ zinc acetate dihydrate and $0.028 \mathrm{~g} \mathrm{~mL}^{-1}$ ethanolamine in 2- 
methoxyethanol). The substrate was annealed on a hot plate at $200{ }^{\circ} \mathrm{C}$ for $30 \mathrm{~min}$. An active layer was cast on top of the $\mathrm{ZnO}$ layer in a nitrogen glove box by spin-coating. An anode consisting of $10 \mathrm{~nm} \mathrm{MoO}$ and $100 \mathrm{~nm} \mathrm{Ag}$ layers was sequentially deposited on top of the active layers, through a shadow mask, by thermal evaporation in a vacuum chamber. The resulting device configuration was an ITO (120-160 nm)/ZnO (30 nm)/active layer/ $\mathrm{MoO}_{x}(10 \mathrm{~nm}) / \mathrm{Ag}(100 \mathrm{~nm})$ with an active area of 7.1 $\mathrm{mm}^{2}$. Current density-voltage curves were measured using a source-measure unit (ADCMT Corp., 6241A) under AM 1.5 G solar illumination at $100 \mathrm{~mW} \mathrm{~cm} \mathrm{~cm}^{-2}(1$ sun, monitored by a calibrated standard cell, Bunko Keiki SM-250KD) from a $300 \mathrm{~W}$ solar simulator (SAN-EI Corp., XES-301S). The EQE spectra were measured by a Bunko Keiki model BS-520BK equipped with a Keithley model 2401 source meter. The monochromated light power was calibrated by a silicon photovoltaic cell, Bunko Keiki model S1337-1010BQ.

\section{Space-charge-limited current (SCLC)}

The SCLC device structures consisted of an ITO/PEDOT:PSS/ active layer (100-200 $\mathrm{nm}) / \mathrm{Au}$ for the hole, and $\mathrm{Al} /$ active layer $(\sim 200 \mathrm{~nm}) / \mathrm{LiF} / \mathrm{Al}$ for the electron. The other procedures are similar to those of the OPV device. The mobility was determined by fitting a current density-voltage curve into the Mott-Gurney law, $J=9 \varepsilon_{0} \varepsilon_{\mathrm{r}} \mu V^{2}\left(8 L^{3}\right)^{-1}$, where $\varepsilon_{0}$ is the permittivity of free space, $\varepsilon_{\mathrm{r}}$ is the dielectric constant of the material, $\mu$ is the mobility, $V$ is the voltage drop across the device, and $L$ is the thickness of the active layer.

\section{Conflicts of interest}

There are no conflicts to declare.

\section{Acknowledgements}

This work was supported by the Japan Society for the Promotion of Science (JSPS) KAKENHI Grant-in-Aid for Scientific Research (A) (Grant No. JP16H02285) and the PRESTO program (Grant No. JPMJPR15N6) from the JST of Japan.

\section{References}

1 A. J. Heeger, Adv. Mater., 2014, 26, 10.

2 L. Dou, Y. Liu, Z. Hong, G. Li and Y. Yang, Chem. Rev., 2015, 115, 12633.

3 Y. Ma, Z. Kang and Q. Zheng, J. Mater. Chem. A, 2017, 5, 1860. 4 Y. Yan, X. Liu and T. Wang, Adv. Mater., 2017, 29, 1601674.

5 M. Pfannmöller, W. Kowalsky and R. R. Schröder, Energy Environ. Sci., 2013, 6, 2871.

6 A. J. Moulé and K. Meerholz, Adv. Funct. Mater., 2009, 19, 3028.

7 H. Utzat, S. D. Dimitrov, S. Wheeler, E. Collado-Fregoso, P. Shakya Tuladhar, B. C. Schroeder, I. McCulloch and J. R. Durrant, J. Phys. Chem. C, 2017, 121, 9790.

8 H. Benten, D. Mori, H. Ohkita and S. Ito, J. Mater. Chem. A, 2016, 4, 5340 .
9 L. Lu, M. A. Kelly, W. You and L. Yu, Nat. Photonics, 2015, 9, 491.

10 T. Kumari, S. M. Lee, S.-H. Kang, S. Chen and C. Yang, Energy Environ. Sci., 2017, 10, 258.

11 N. E. Jackson, K. L. Kohlstedt, B. M. Savoie, M. O. de la Cruz, G. C. Schatz, L. X. Chen and M. A. Ratner, J. Am. Chem. Soc., 2015, 137, 6254.

12 S. Yoshikawa, A. Saeki, M. Saito, I. Osaka and S. Seki, Phys. Chem. Chem. Phys., 2015, 17, 17778.

13 C. J. Mueller, E. Gann, C. R. Singh, M. Thelakkat and C. R. McNeill, Chem. Mater., 2016, 28, 7088.

14 I. Osaka and K. Takimiya, Adv. Mater., 2017, 29, 1605218.

15 J. C. Bijleveld, A. P. Zoombelt, S. G. J. Mathijssen, M. M. Wienk, M. Turbiez, D. M. de Leeuw and R. A. J. Janssen, J. Am. Chem. Soc., 2009, 131, 16616.

16 A. T. Yiu, P. M. Beaujuge, O. P. Lee, C. H. Woo, M. F. Toney and J. M. J. Fréchet, J. Am. Chem. Soc., 2012, 134, 2180.

17 J. W. Jung, F. Liu, T. P. Russell and W. H. Jo, Energy Environ. Sci., 2012, 5, 6857.

18 C. B. Nielsen, M. Turbiez and I. McCulloch, Adv. Mater., 2013, 25, 1859.

19 W. Li, K. H. Hendriks, A. Furlan, W. S. C. Roelofs, M. M. Wienk and R. A. J. Janssen, J. Am. Chem. Soc., 2013, 135, 18942.

20 J.-H. Kim, M. Lee, H. Yang and D.-H. Hwang, J. Mater. Chem. A, 2014, 2, 6348.

21 Y. Ji, C. Xiao, Q. Wang, J. Zhang, C. Li, Y. Wu, Z. Wei, X. Zhan, W. Hu, Z. Wang, R. A. J. Janssen and W. Li, Adv. Mater., 2016, 28, 943.

22 W. Li, K. H. Hendriks, M. M. Wienk and R. A. J. Janssen, Acc. Chem. Res., 2016, 49, 78.

23 G. B. Yoon, H.-Y. Kwon, S.-H. Jung, J.-K. Lee and J. Lee, ACS Appl. Mater. Interfaces, 2017, 9, 39502.

24 P. Sonar, H.-S. Tan, S. Sun, Y. M. Lam and A. Dodabalapur, Polym. Chem., 2013, 4, 1983.

25 T. Lei, J.-Y. Wang and J. Pei, Acc. Chem. Res., 2014, 47, 1117. 26 R. Stalder, J. Mei, K. R. Graham, L. A. Estrada and J. R. Reynolds, Chem. Mater., 2014, 26, 664.

27 C.-C. Ho, C.-A. Chen, C.-Y. Chang, S. B. Darling and W.-F. Su, J. Mater. Chem. A, 2014, $2,8026$.

28 Z. Ma, D. Dang, Z. Tang, D. Gedefaw, J. Bergqvist, W. Zhu, W. Mammo, M. R. Andersson, O. Inganäs, F. Zhang and E. Wang, Adv. Energy Mater., 2014, 4, 1301455.

29 C.-C. Ho, C.-A. Chen, C.-Y. Chang, S. B. Darling and W.-F. Su, J. Mater. Chem. A, 2014, 2, 8026.

30 W. Yue, R. S. Ashraf, C. B. Nielsen, E. Collado-Fregoso, M. R. Niazi, S. A. Yousaf, M. Kirkus, H.-Y. Chen, A. Amassian, J. R. Durrant and I. McCulloch, Adv. Mater., 2015, 27, 4702.

31 M. Tomassetti, F. Ouhib, A. Wislez, A.-S. Duwez, H. Penxten, W. Dierckx, I. Cardinaletti, R. A. A. Bovee, G. W. P. van Pruissen, C. Jérôme, J. Manca, W. Maes and C. Detrembleur, Polym. Chem., 2015, 6, 6040.

32 Y. Deng, W. Li, L. Liu, H. Tian, Z. Xie, Y. Geng and F. Wang, Energy Environ. Sci., 2015, 8, 585.

33 S. Nishinaga, H. Mori and Y. Nishihara, Macromolecules, 2015, 48, 2875. 
34 X. Chen, Z. Zhang, J. Liu and L. Wang, Polym. Chem., 2017, 8, 5496.

35 R. S. Ashraf, A. J. Kronemeijer, D. Ian James, H. Sirringhaus and I. McCulloch, Chem. Commun., 2012, 48, 3939.

36 G. W. P. Van Pruissen, F. Gholamrezaie, M. M. Wienk and R. A. J. Janssen, J. Mater. Chem., 2012, 22, 20387.

37 Y. Koizumi, M. Ide, A. Saeki, C. Vijayakumar, B. Balan, M. Kawamoto and S. Seki, Polym. Chem., 2013, 4, 484.

38 M. Ide, Y. Koizumi, A. Saeki, Y. Izumiya, H. Ohkita, S. Ito and S. Seki, J. Phys. Chem. C, 2013, 117, 26859.

39 M. Karakawa and Y. Aso, Macromol. Chem. Phys., 2013, 214, 2388.

40 C. Lu, H.-C. Chen, W.-T. Chuang, Y.-H. Hsu, W.-C. Chen and P.-T. Chou, Chem. Mater., 2015, 27, 6837.

41 K. Wang, W. y. Su, B. Guo, X. Guo, M. Zhang and Y. Li, Synth. Met., 2016, 220, 134.

42 M. Ide, Y. Koizumi and A. Saeki, J. Photopolym. Sci. Technol., 2016, 29, 565.

43 G. K. Dutta, A.-R. Han, J. Lee, Y. Kim, J. H. Oh and C. Yang, Adv. Funct. Mater., 2013, 23, 5317.

44 I. Meager, M. Nikolka, B. C. Schroeder, C. B. Nielsen, M. Planells, H. Bronstein, J. W. Rumer, D. I. James, R. S. Ashraf, A. Sadhanala, P. Hayoz, J.-C. Flores, H. Sirringhaus and I. McCulloch, Adv. Funct. Mater., 2014, 24, 7109.

45 G. Kim, S.-J. Kang, G. K. Dutta, Y.-K. Han, T. J. Shin, Y.-Y. Noh and C. Yang, J. Am. Chem. Soc., 2014, 136, 9477.

46 G. Kim, H. Kim, M. Jang, Y. K. Jung, J. H. Oh and C. Yang, J. Mater. Chem. C, 2016, 4, 9554.

47 H. J. Cho, S.-J. Kang, S. M. Lee, M. Jeong, G. Kim, Y.-Y. Noh and C. Yang, ACS Appl. Mater. Interfaces, 2017, 9, 30755.

48 J. S. Wilson, N. Chawdhury, M. R. A. Al-Mandhary, M. Younus, M. S. Khan, P. R. Raithby, A. Köhler and R. H. Friend, J. Am. Chem. Soc., 2001, 123, 9412.
49 M. S. Chen, J. R. Niskala, D. A. Unruh, C. K. Chu, O. P. Lee and J. M. J. Fréchet, Chem. Mater., 2013, 25, 4088.

50 M. Ide, A. Saeki, Y. Koizumi, T. Koganezawa and S. Seki, J. Mater. Chem. A, 2015, 3, 21578.

51 M. Ide and A. Saeki, Chem. Lett., 2017, 46, 1133.

52 Y. Wang, F. Yang, Y. Liu, R. Peng, S. Chen and Z. Ge, Macromolecules, 2013, 46, 1368.

53 L. Dou, W.-H. Chang, J. Gao, C.-C. Chen, J. You and Y. Yang, Adv. Mater., 2013, 25, 825.

54 L. Ying, F. Huang and G. C. Bazan, Nat. Commun., 2017, 8, 14047.

55 X. Liu, Y. Sun, L. A. Perez, W. Wen, M. F. Toney, A. J. Heeger and G. C. Bazan, J. Am. Chem. Soc., 2012, 134, 20609.

56 T. Erb, U. Zhokhavets, G. Gobsch, S. Raleva, B. Stühn, P. Schilinsky, C. Waldauf and C. J. Brabec, Adv. Funct. Mater., 2005, 15, 1193.

57 M. A. Evans, D. C. Smith, J. M. Holub, A. Argenti, M. Hoff, G. A. Dalglish, D. L. Wilson, B. M. Taylor, J. D. Berkowitz, B. S. Burnham, K. Krumpe, J. T. Gupton, T. C. Scarlett, R. W. Durham Jr and I. H. Hall, Arch. Pharm. Pharm. Med. Chem., 2003, 336, 181.

58 Y. Xu, Y. Jin, W. Lina, J. Peng, H. Jiang and D. Cao, Synth. Met., 2010, 160, 2135-2142.

59 X. Guo, R. P. Ortiz, Y. Zheng, M.-G. Kim, S. Zhang, Y. Hu, G. Lu, A. Facchetti and T. J. Marks, J. Am. Chem. Soc., 2011, 133, 13685.

60 K. Chung, M. S. Kwon, B. M. Leung, A. G. Wong-Foy, M. S. Kim, J. Kim, S. Takayama, J. Gierschner, A. J. Matzger and J. Kim, ACS Cent. Sci., 2015, 1, 94.

61 M. Sasikumar, D. Bharath, G. S. Kumar, N. R. Chereddya, S. Chithiravel, K. Krishnamoorthy, B. Shanigaram, K. Bhanuprakash and V. J. Rao, Synth. Met., 2016, 220, 236. 